\title{
Editorial: Em Defesa das Publicações em Português
}

Prezados leitores, recentemente adotamos a política de publicar somente artigos em português. Aparentemente, tal medida vai na contramão do movimento que vários periódicos nacionais vêm adotando para se internacionalizar, o que, em um primeiro momento, pareceria ilógico ou irracional. Mas, como apontarei aqui, além das já boas justificativas que outros colegas brasileiros já apontaram para se produzir em português (Alcadipani, 2017; Bertero, Alcadipani, Cabral, Faria \& Rossoni, 2013; Goulart \& Carvalho, 2008), sem esquecer dos contrapontos daqueles que advogam um maior engajamento na produção em inglês (Cabral \& Lazzarini, 2011; Diniz, 2017; Farias, 2017), adiciono mais dois argumentos: um lógico, em que uma internacionalização plena de periódicos brasileiros paradoxalmente levaria a uma não internacionalização da produção nacional; outro utilitário, em que evidencio que artigos publicados em português são mais acessados, mais baixados e significativamente mais citados do que os de língua inglesa e espanhola no Spell.

Devo ressaltar que o foco não é criticar de uma forma geral o movimento de internacionalização da produção nacional, mas sim questionar especificamente as razões pelas quais os periódicos nacionais vêm abdicando de publicar na língua mãe para embarcar no vernáculo da língua inglesa, com o anseio de almejar a terra prometida do leitor estrangeiro e, melhor ainda, ser citado no meio internacional. Assim, eu gostaria de começar questionando se realmente uma citação de um periódico internacional vale mais do que uma citação de um periódico nacional.

Boa parte do discurso e da retórica acerca da internacionalização da produção parte do pressuposto de que a "boa" citação é aquela que parte de periódicos internacionais e, melhor ainda, aquela que parte de periódicos bem ranqueados no fator de impacto do Journal Citation Reports (JCR). A vontade é tamanha da citação internacional que, na maioria dos casos, nem se questiona a fonte da citação. Basta ser citado, não importa por qual periódico, desde que seja internacional. E ainda também não importaria se essas citações fossem feitas por periódicos nacionais, desde que estivessem em bases internacionais como o JCR e o SCOPUS. Ou seja, trocando em miúdos, não importa a fonte da citação, desde que ela afete as métricas dos indexadores tidos como referência internacional. Ao ponto que se olharmos as citações recebidas em 2017 no JCR dos dois únicos periódicos brasileiros que temos na área de administração, vemos, por exemplo, que das 20 citações recebidas para compor o impacto da Revista Brasileira de Gestão de Negócios (RBGN)ํㅜ 7 são de periódicos nacionais (35\%) e os

1 A RBGN teve em 2017 um JCR de 0,278, 0 que significa que, na média, 28\% dos artigos publicados nos dois anos anteriores foram citados.
Luciano Rossoni (iD, Editor da RECADM UniGranRio, Brasil Irossoni@gmail.com 
outros são de periódicos de menor impacto ou até fora do $\mathrm{JCR}^{2}$, com muitos autores de origem asiática, hispânica e italiana. Já a Revista de Administração de Empresas (RAE), com toda sua trajetória e dominância local no campo de administração, tem um JCR também baixo, de 0,404, no qual das 38 citações recebidas, 17 são de revistas nacionais (45\%) e, das quais, 7 são autocitações. As demais citações recebidas, como no caso da RBGN, têm em sua maioria autores de origem não anglo saxônica.

O fato é que os dois casos práticos de internacionalização desses periódicos no indexador mais "respeitado" do mundo demonstram que a almejada citação pelos veículos de alto impacto não ocorreu, levando-nos, pelo menos no estágio atual, a uma posição ainda mais periférica no jogo da ciência, já que há indícios de queda no protagonismo local em termos de uso das citações por autores nacionais ${ }^{3}$. No jargão popular, tal internacionalização em curso indica uma preferência "por ser rabo de tubarão ao invés de cabeça de sardinha". Ao meu ver, isso esboça a tendência cada vez maior de subordinar o conhecimento local a uma lógica internacional que não tem nada a ver com o conteúdo e a qualidade em si do que é produzido, mas sim porque há um interesse em homogeneizar a roupagem de tal produção sob uma lógica acadêmica que é estruturada sob a égide de poucos centros legitimados como produtores do conhecimento.

Tais centros capturam o que é produzido nas periferias por meio de pesquisadores que atuam como atravessadores do conhecimento local, auferindo a esses últimos o papel de brokers no processo de recolonização do conhecimento. Tais atravessadores usam muitas vezes o argumento dúbio de que a forma correta de se internacionalizar é aquela induzida pelo modo que eles costumam operar, em detrimento de qualquer outra forma de internacionalizar, ou, até mesmo, fazendo o jogo duplo de afagar os colegas localmente, mas distanciando-se deles internacionalmente, até para manter sua posição estratégica.

Talvez os problemas de internacionalização dos periódicos sejam devido às estratégias equivocadas ou não suficientes. Como aponta o ex-editor da RAE, "na mesma medida em que os programas de pós-graduação pressionam seus professores para publicarem 'internacionalmente', os periódicos nacionais também precisam se internacionalizar. Aqueles periódicos que não forem proativos no contexto da internacionalização não só continuarão invisíveis para autores estrangeiros, como também perderão importância para um grupo relevante de autores brasileiros" (Diniz, 2017, p. 361). Então, se a internacionalização não somente ameaça nossa projeção global, mas também nosso domínio local, o que um periódico poderia fazer?

Segundo Diniz (2017), os periódicos comumente vêm buscando: 1) publicar em inglês; 2) aderir a editoras comerciais estrangeiras; 3 ) investir em chamadas de trabalho internacionais. Em relação à primeira estratégia, o que

2 Artigos presentes, por exemplo, no Emerging Sources Citation Index computam citações, mas não estão presentes no JCR.

3 Como apontam dados de citações do Spell, a Revista Contabilidade \& Finanças e a Revista de Administração Contemporânea vêm sendo os periódicos mais citados na área nos últimos anos ambas fora do SCOPUS e do JCR. 
vemos de forma cada vez mais frequente são periódicos nacionais abdicarem do português, aceitando publicações somente em inglês. Há alguns poucos que são bilingues e sustentam-se financeiramente, bem como alguns que empurram os custos da tradução para os autores. Independentemente de como, o pressuposto é de que um artigo em língua inglesa alcançaria um público maior. Será mesmo? Creio que não.

Como peça de comunicação, um artigo científico disputa espaço com demais artigos. Assim, se considerarmos o universo de publicações em inglês em 2017 na área de management na base Crossref, que é a mais ampla internacionalmente, um artigo nacional publicado lá fora disputaria a atenção com outros 134.984 artigos. No Spell, que é nacional, o mesmo artigo disputaria a atenção com outros 2.991 artigos. Em termos de probabilidades, considerando que o número de autores internacionais, tomados como prováveis leitores com interesse nas áreas de gestão é, hipoteticamente, 36,18 vezes maior que o nacional ${ }^{4}$, a probabilidade de leitura de um artigo no Brasil ainda seria maior em 24,7\%. Isso se desconsiderarmos ainda os efeitos de estratificação e prestígio dos periódicos mais centrais, que são poderosos em detrimento dos nacionais. Logo, não daria para dizer que tal exposição aumentaria as chances de um artigo ser lido e citado.

Acerca da segunda estratégia, que é o uso de editoras comerciais estrangeiras, Diniz (2017, p. 362) argumenta que é "fato que essas grandes editoras conseguem garantir a qualidade necessária à disseminação internacional do conhecimento científico. [...] Isso poderia sugerir que o caminho natural para nossos periódicos, que também querem ganhar um lugar de destaque junto aos principais periódicos internacionais, deveria ser mesmo o de migração para uma grande editora." Estratégia que é corroborada por Farias (2017, p. 401), ex-editor da Brazilian Administration Review, apontando que, "para competir no mercado editorial internacional, se estabelece a perspectiva de que o caminho para a internacionalização passa pela profissionalização editorial, em que um Publisher (casa editorial) será responsável pelas partes operacional e gerencial, e a parte acadêmico-científica será responsabilidade de um corpo editorial diversificado e de excelente reputação".

Tal estratégia de incorporação de periódicos nacionais por publishers internacionais como Sage, Elsevier, Emerald, Springer, Wiley, entre outros, do ponto de vista individual do periódico, aparentemente seria uma boa alternativa se tais publishers conseguissem, de alguma forma, transferir seu conhecimento, capilaridade e prestígio para os periódicos emergentes. Se conseguem, isso não vem apresentando grandes resultados. Como apontou Diniz (2017, p. 362), citando o estudo de Larivière, Haustein e Mongeon (2015), "particularmente nas ciências sociais, o impacto médio dos artigos publicados nos periódicos que migraram para as grandes editoras permaneceu abaixo da média mundial. Ou seja, essa estratégia não produziu nenhuma melhoria no impacto dos periódicos, mesmo 10 anos após a migração".

A razão da ineficácia de tal estratégia é óbvia: o prestígio de tais publishers não vem do conhecimento, qualidade e capilaridade editoriais, mas

4 Para checar a esse número, considerei a diferença de produção nacional no SCOPUS em relação ao somatório da internacional na área de Business, Management and Accounting. 
simplesmente porque eles hospedam os principais periódicos mundiais. De tal maneira que não se vislumbra qualquer caráter identitário ou de diferenciação entre periódicos presentes em um publisher em particular comparado com qualquer outro. Ao mesmo tempo, é extremamente frequente, por meio de acordos comerciais, um periódico migrar de um publisher para outro, como ocorreu, por exemplo, com o Journal of Management, que migrou da Elsevier para a SAGE em 2005, sem grandes alterações de identidade.

Retrato ainda da baixa ou pouca influência do publisher na qualidade dos periódicos é o grau de independência e desacoplamento que o processo editorial-científico tem do processo editorial-gerencial. Tomando como referência somente três periódicos importantes da área de management editados pela mesma editora, a SAGE, Journal of Management (pertencente a Southern Management Association), Administrative Science Quarterly (de propriedade da Samuel Curtis Johnson Graduate School of Management, Cornell University) e Organization Studies (pertencente ao European Group for Organizational Studies - EGOS), é possível notar que todos eles apresentam linha e processos editoriais totalmente distintos, inclusive no que se refere aos critérios de qualidade e relevância, bem como no estilo de redação e apresentação dos artigos. A SAGE, em todos os casos, se apresenta como parte do processo quase que exclusivamente somente após o artigo ser aprovado, pois até as ferramentas de gestão editorial, como o Manuscript Central, não são de sua propriedade e tendem a ser compartilhados por muitas editoras. Nesse processo, pouco se incorpora da editora na identidade dos periódicos, muito menos provável ainda que algo se altere em termos de qualidade dos artigos.

Assim, a crença disseminada na capacidade do publisher de alavancar a internacionalização dos periódicos serve muito mais para manter um mito racionalizado, que ilude especialmente aqueles periódicos ainda fora do sistema que buscam ascender ao mundo das publicações internacionais. Tal busca alimenta interesses puramente comerciais de tais editoras, até porque elas se abstêm de todo o processo científico. Os publishers, sabidamente, utilizam-se das crenças na eficácia de seu mito construído para avançar particularmente em mercados emergentes, nitidamente porque vêm sendo ameaçados por uma série de boicotes de países e universidades em prol de um modelo de ciência aberto. Isso porque é cada vez fica mais difícil de se justificar os altos valores cobrados por tais publishers para vender acesso a um produto, que, como bem apontaram Goulart e Carvalho (2008), foi apropriado da força de trabalho dos pesquisadores que, por sua vez, têm boa parte de suas pesquisas financiadas por recursos públicos. Publishers internacionais hoje, infelizmente, não produzem: eles simplesmente usam do copyright para se apropriar, ao mesmo tempo, do trabalho alheio e do recurso público. E enquanto o mundo vem combatendo tal domínio comercial, há os que o defendem no objetivo de não se alterar as regras do jogo que eles vêm tentando dominar. Com isso, corremos o risco de ainda sustentar a tecnologia obsoleta mais lucrativa da história (Schmitt, 2014) ${ }^{5}$.

A terceira estratégia, como aponta Diniz (2017), seria a criação de chamadas de trabalhos incorporando pesquisadores internacionais como editores especiais no objetivo de obter pareceristas estrangeiros e, em alguns

5 Definitivamente 0 autor não conhece 0 sistema de cartórios brasileiro para fazer tal afirmação. 
casos, atrair textos de autores internacionais. Decorrente de tal estratégia, ainda há a expectativa de que tais participantes acabem aceitando fazer parte do comitê permanente. Somadas a essas estratégias, que podemos enquadrá-las como de relacionamento, ainda há a possibilidade de convidar artigos de autores renomados, muitas vezes pagando pelo artigo diretamente, ou como contrapartida pelo autor estrangeiro ter aceitado participar de alguma atividade renumerada no país. Isso já ocorreu em vários periódicos nacionais, os quais mostram, com muito orgulho inclusive, que possuem artigos altamente citados de tais autores renomados.

Em comum entre essas parcerias com autores internacionais está a crença de que os autores locais não são suficientes, ou literalmente não prestam para a internacionalização. Isso fica nítido, por exemplo, na citação atribuída a Fradkin (2017) feita por Farias (2017, p. 402):

[...] a internacionalização bem-sucedida de periódicos, além do conteúdo em inglês de boa qualidade, deve contemplar outros dois elementos: que a instituição do primeiro autor e os membros do conselho editorial pertençam a um país nativo de língua inglesa, e que os artigos descrevam estudos empíricos. Segundo esse autor, para que haja uma internacionalização de sucesso, os periódicos devem assumir dois caminhos: aumentar o número de artigos publicados em língua inglesa e a colaboração com autores nativos de língua inglesa. A chave para a internacionalização das revistas brasileiras envolve o aporte brasileiro à expertise de língua-franca (inglês), e a especialização, em termos de editores experientes, revisores, editores e autores. São necessários profissionais que sejam nativos de países onde o inglês é a língua oficial para elevar os padrões das revistas no Brasil (Fradkin, 2017).

Em comum entre todas essas estratégias, há um ponto: não somos suficientes, talvez nem merecedores, de termos uma academia internacional genuinamente brasileira. É o que se apresenta, mas que nunca é dito, apesar de sempre estar implícito.

Assumindo tal insuficiência como uma verdade temporária, e se nossas estratégias de internacionalização de periódicos fossem levadas a cabo? Teríamos de fato então uma internacionalização da produção? Eu argumento que tais estratégias de internacionalização dos periódicos levariam, paradoxalmente, a uma não internacionalização da produção. Para ilustrar tal argumento, pensemos numa sequência de ações estratégicas hipotéticas de um periódico nacional em busca de internacionalização. Primeiramente, ele somente publicaria artigos em inglês. Como isso não é suficiente, havendo recursos, pagaria para ser incorporado por um grande publisher. Além disso, o periódico não somente buscaria abrir chamadas internacionais com autores estrangeiros, mas também faria um esforço de recrutamento de avaliadores estrangeiros. Com o tempo, seria construído um corpo editorial científico e em especial, seu editor chefe, com pesquisadores internacionais. Isso tudo aumentaria, pelo menos hipoteticamente, as chances do periódico ser aceito no SCOPUS e, mais ainda, atingir a glória de ser listado no JCR. Nesse momento e em especial, se o periódico não possuir o adjeto Brazilian no título, cada vez mais autores internacionais submeteriam artigos para tal periódico que, em um segundo momento, ainda aumentaria mais a base de revisores. Consequentemente, para ser caracterizado como internacional, cada vez menos espaço seria dado aos pobres autores brasileiros. Com isso, conclui-se o fatídico projeto de internacionalização. 
Na situação hipotética descrita, não é muito difícil deduzir logicamente que o somatório de estratégias de internacionalização dos periódicos levaria exatamente ao efeito de uma não internacionalização justamente daquilo que mais desejamos, que é a produção e o conhecimento local. Então, em termos de eficácia, a internacionalização de periódicos majoritariamente almejada é paradoxalmente nula. E é esse argumento que queria demonstrar, pois, no tipo ideal, a única coisa que se manteria nacional, e olhe lá, seria a propriedade do periódico. A propriedade do periódico importa? Para os periódicos da Academy of Management sim, mas para outros, tenho dúvidas. Por exemplo, eu desafio vocês a checarem quantos colegas conhecem a propriedade, por exemplo, do periódico Organization Science.

Além dos argumentos que esbocei, gostaria de mostrar alguns dados que reforçam a importância de se publicar em português. Não me aterei aqui à discussão da produção do conhecimento local em si (ver mais em Goulart, 2018), porque esse é construído em português e, sim, deve ser preservado em português enquanto patrimônio cultural. A língua não é somente meio, mas faz parte de tal construção, atribuindo sentido e significado único ao que vivenciamos e pensamos, de difícil tradução e apropriação. Deve-se ressaltar também que o Brasil é um país de baixa proficiência na língua inglesa ${ }^{6}$, o que acaba refletindo no baixo domínio dos estudantes de pós-graduação, levando-os a preferir a leitura em português.

Tomando como base dados das publicações no Spell entre 2012 e 2014, na Figura 1, pode-se ver que os artigos em português são significativamente mais acessados na média do que aqueles em língua inglesa e espanhola. O número de downloads médio também é significativamente maior. Devo ressaltar que algum leitor poderia atribuir o maior acesso e o maior número de downloads ao uso de termos de busca em português, que acaba desconsiderando as demais línguas. Isso definitivamente não ocorre: independentemente da língua em que o artigo é publicado no Spell, os campos de busca também estão presentes em português.

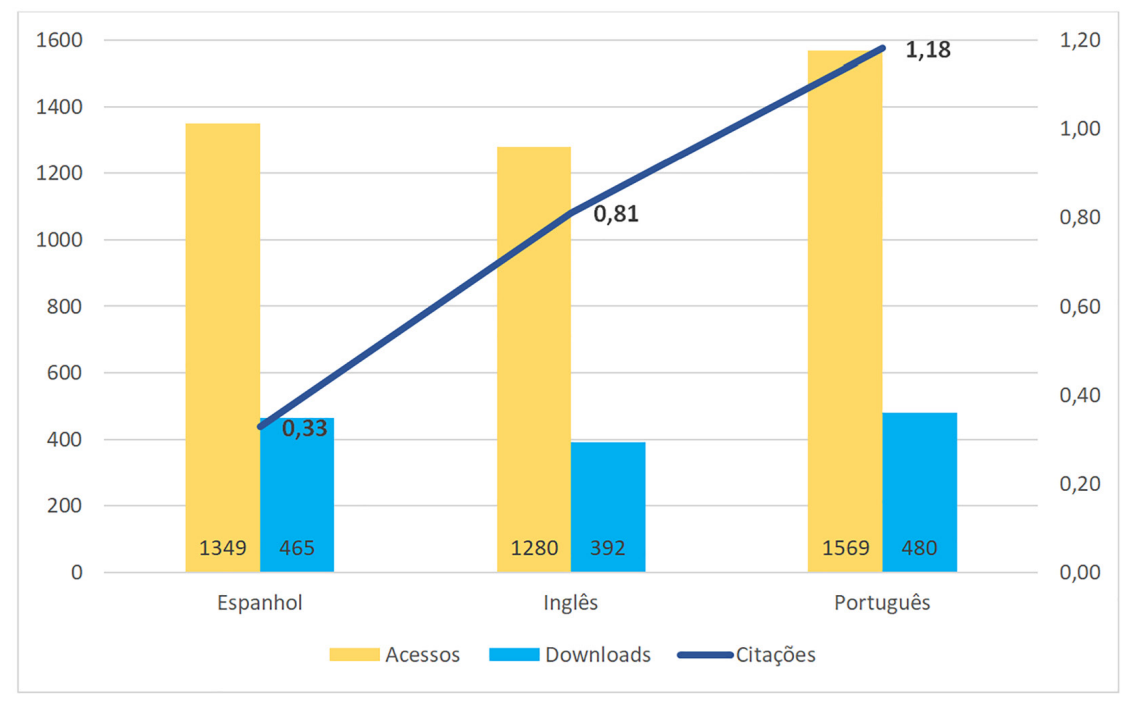

Figura 1. Média de Citações, Acessos e Downloads no Spell (2012-2014).

6 Ver posição do Brasil no rank de proficiência em inglês em: https://www.ef.com.br/epi/regions/latinamerica/brazil/ 
Mais interessante ainda é a média de citações recebidas dos artigos publicados em tal período: os artigos em português tendem, na média, serem citados 1,18 vezes, enquanto os artigos em inglês são citados, em média, 0,81 vezes e os em espanhol citados em 0,33 vezes. Então, se o interesse de um periódico é ser citado, não resta dúvidas que a probabilidade de isso ocorrer em português é significativamente maior.

Um leitor mais cético poderia questionar se o efeito da língua em tais citações remete à proporção de mais artigos em inglês em alguns periódicos menos citados ou até mesmo a concentração no ano mais recente, que tende a acumular menos citações. Para controlar tais efeitos, fiz uma análise da variância considerando o efeito tanto do periódico, quanto do ano (detalhes sobre os procedimentos no apêndice). Como visto na Figura 2, para qualquer um dos anos, as médias marginais estimadas de citação dos artigos em português são significativamente maiores, nos quais ao controlar o efeito dos periódicos, a magnitude da diferença entre médias é ainda maior que a média simples. Por exemplo, os artigos publicados em português em 2012 têm uma média estimada de 1,4 citações, enquanto os artigos publicados em inglês no mesmo ano têm uma média de 0,76 citações.

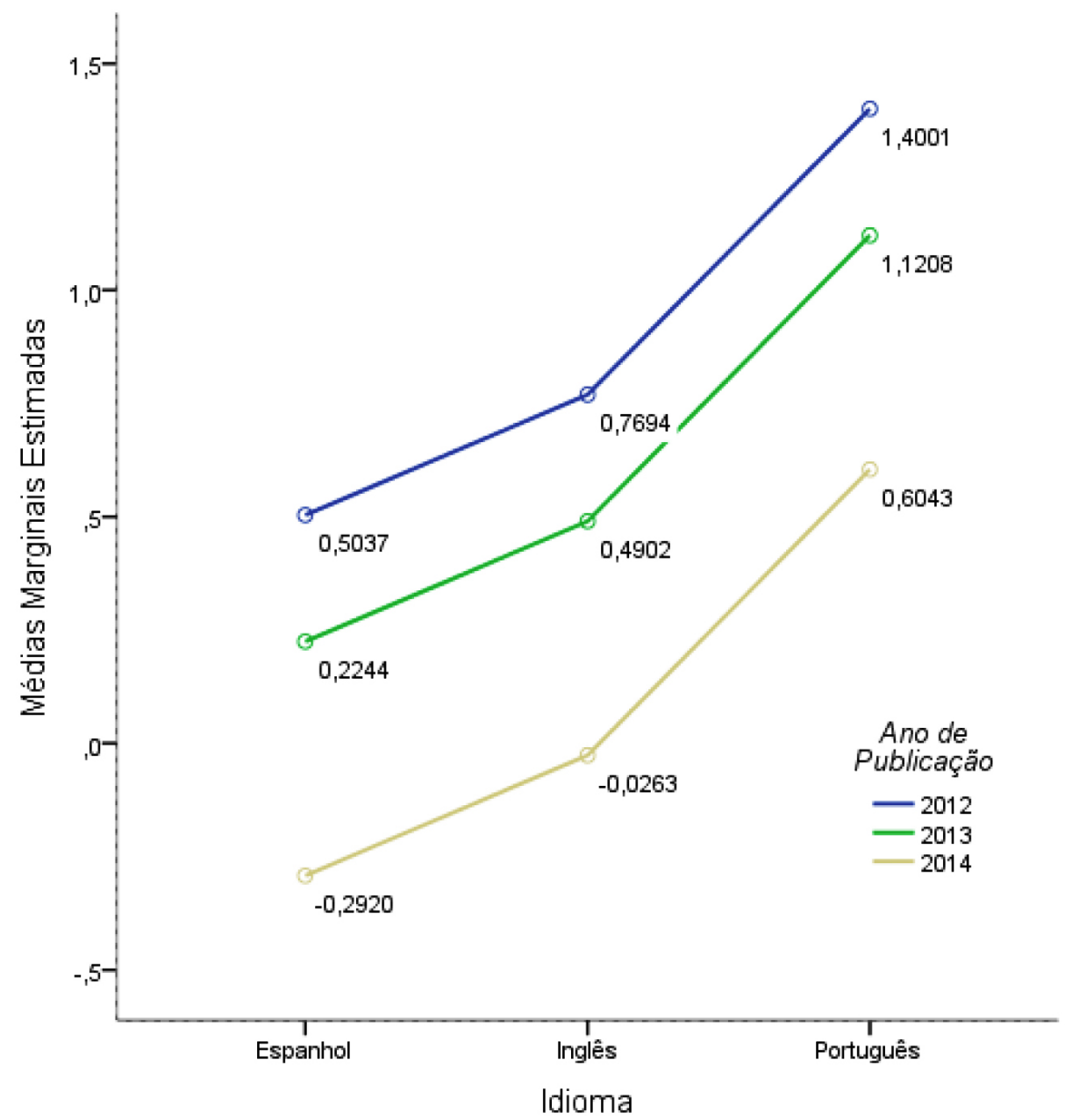

Figura 2. Médias Estimadas por Ano (Dados: Spell 2012-2014). 
Em síntese, o que eu gostaria de demonstrar com esses dados é que, se um editor está preocupado em receber mais citações, não há dúvidas que utilitariamente o português é mais efetivo. Pode-se indagar que tais citações ocorreram numa base local. Só que artigos brasileiros são cada vez mais frequentes nas bases internacionais que, por sua vez, tendem a ser mais citados por artigos brasileiros. Assim, ironicamente, publicar em português possa até ser um bom negócio para aqueles que buscam ganhar destaque nas bases internacionais.

Finalizando, nesse editorial busquei esboçar um argumento lógico e outro empírico para defender as publicações em português. Há vários outros argumentos morais e racionais que se sobrepõem aos meus argumentos, como vários colegas já apontaram. E todos eles remetem à importância de se defender o uso da língua natal como instrumento de preservação e resistência a uma lógica global homogeneizante do conhecimento. Eu adicionaria ainda o prazer de se escrever em nossa língua, que mesmo sendo usada em textos "duros" como os acadêmicos, ainda são possíveis de transmitir coisas belas. Não que não exista beleza em outras línguas, mas uma língua natal exprime uma forma de existência que só é comum para quem se socializou nela. Logo, para nós, defender o português é uma forma de defender também nossa existência como sociedade brasileira.

\section{Nesta Edição}

Nesta terceira e última edição de 2018, não temos mais grandes novidades em termos de layout e incorporação de tecnologias no portal como nas edições anteriores. No entanto, gostaria de ressaltar que agora temos um perfil da RECADM no Google Acadêmico. Tal perfil facilita o acompanhamento das citações que os artigos publicados na revista recebem, especialmente de fontes que não estão vinculadas a bases como Spell, Scopus e demais. Até o dia 25 de julho deste ano, recebemos um total de 837 citações, das quais 655 ocorreram nos últimos cinco anos, em que o índice $H$ foi 14. Isso significa que temos 14 artigos que foram citados 14 vezes ou mais. Esses números, para nós, significam duas coisas: a primeira é que nossos artigos estão sendo cada vez mais citados, o que é motivo de orgulho; a segunda é que o número de citações não é concentrado em poucos artigos, como ocorre em alguns outros periódicos que têm a citação extremamente alavancada por artigos de poucos autores renomados. Isso aponta para certo grau de igualdade na exposição dos artigos e autores.

No que se refere aos artigos desta edição, eles se enquadram em temáticas variadas, como já de praxe. Contudo, há algumas palavras que se ressaltam. Dois artigos remetem diretamente à questão da política, um enquanto comportamento, outro como padrão. A política e as diferentes facetas que ela toma nas organizações sempre foi algo áspero para a administração. Com tal intensidade que muitas vezes ela foi excluída do debate, seja pelo interesse da área da gestão de se legitimar como campo se diferenciando da ciência e da filosofia política, ou até mesmo pelo viés utilitarista que leva a área a se preocupar em maior grau com critérios de eficiência. E isso ocorreu apesar de todos os argumentos weberianos e de Guerreiro Ramos de que a administração é uma atividade essencialmente política. Há ainda outros dois artigos que remetem a 
questões socioambientais e de sustentabilidade, cuja preocupação atual, mas não tão recente, surgiu de debates políticos acerca de como as organizações lidam com suas externalidades. Novamente, isso ressalta que a administração necessariamente reflete em parte o contexto político. Por fim, temos um artigo que lida com o problema do compartilhamento do conhecimento tácito que, novamente, envolve questões políticas no que se refere aos mecanismos que o motivam, e outro artigo que discute sobre a fotografia, ou melhor, a prática de fotografar como instrumento de investigação. Essa discussão é extremamente pertinente porque háainda aqueles que acreditam que a fotografiaé uma espécie de prova cabal, neutra, sem interferência do fotógrafo. Pelo contrário, como muito bem apontou Ansel Adams, "não fazemos uma foto apenas com uma câmara; ao ato de fotografar trazemos todos os livros que lemos, os filmes que vimos, a música que ouvimos, as pessoas que amamos." Inclusive colocamos nossos interesses na fotografia, como muito bem apontou Sebastião Salgado, que ressaltava que ele não fazia fotografias, mas sim política.

O primeiro artigo, "Comportamento Político nas Organizações: Mecanismos de Intervenção", de autoria de Rosária de Fátima Segger Macri Russo, Fabiano Rodrigues, Renato Russo e Abraham Sin Oih Yu, identifica a percepção de executivos brasileiros sobre as formas de comportamento político nas organizações e mecanismos de intervenção correlatos. Como resultado, a pesquisa aponta para uma visão menos negativa dos respondentes sobre o conceito de comportamento político, quando comparada à literatura. A principal contribuição gerencial se concentra na discussão sobre mecanismos de intervenção nas organizações que promovam uma dinâmica do comportamento político favorável aos objetivos organizacionais. Do ponto de vista acadêmico, amplia-se a discussão dos efeitos positivos do comportamento político e apresentam-se mecanismos de intervenção para pesquisas futuras sobre política nas organizações.

No segundo artigo, "Relações Multiníveis e Inovação Sustentável: O Programa Veículo Elétrico da Itaipu Brasil", os autores Andréa Torres Barros Batinga de Mendonça, Sieglinde Kindl da Cunha e Thiago Cavalcante Nascimento analisaram as relações multiníveis e a transição para ecoinovação a partir do caso do Programa Veículo Elétrico da Itaipu Brasil. Os principais resultados evidenciam a importância de grandes organizações como agentes "empreendedores" e da formação de parcerias nos nichos tecnológicos como fatores que influenciam a criação das ecoinovações, que passam a modificar os valores compartilhados e as instituições dos agentes do nível meso, em um processo de influência bottom up. Além disso, as mudanças do nível macro exerceram pressão sobre os níveis meso e micro em um processo de influência top down.

O terceiro artigo, de autoria de Breno Penha Rêgo, Alessandra Carvalho de Vasconcelos e José Glauber Cavalcante dos Santos, intitulado "Efeitos da Estrutura de Governança Corporativa e das Características Institucionais no Disclosure Socioambiental" analisa a influência da estrutura de governança corporativa das companhias abertas brasileiras e de suas características institucionais na qualidade do disclosure socioambiental. Os resultados apontaram que a proporção de membros independentes no conselho de administração, como estrutura de governança e a participação da empresa 
no ISE, como característica institucional, são capazes de influenciar o nível do disclosure socioambiental. Dessa forma, há evidências de que os conflitos de agência e as pressões de legitimidade podem agir sobre o comportamento socioambiental da empresa perante os stakeholders.

No quarto artigo, intitulado "Motivadores ao Compartilhamento de Conhecimento Tácito em Organizações Intensivas em Conhecimento", Patrícia Fernanda Dorow, Dorzeli Salete Trzeciak e Gregório Jean Varvakis Rados evidenciam os motivadores no compartilhamento do conhecimento tácito, de acordo com a percepção de radiologistas integrantes de grupos de trabalhos de organizações intensivas em conhecimento. Os resultados contribuem para o avanço da teoria existente e apontam que quando o indivíduo percebe um ambiente favorável ao compartilhamento do conhecimento, onde é reconhecido pelo seu conhecimento, ele é motivado a compartilhar, pois identifica oportunidades de aprender ao discutir casos desafiadores com seus colegas por meio de práticas que são efetivas devido às características peculiares dos grupos e da percepção que os mesmos possuem da ação de compartilhar conhecimento tácito.

O quinto artigo, "A Política de Recompensa e Promoção Influencia a Motivação do Trabalhador?", de coautoria de Marcio Gonçalves de Pinho, Tara Keshar Nanda Baidya, Marta Correa Dalbem e Eduardo Henrique de Sousa Salvino, estuda a influência da política de recompensa e promoção na motivação do trabalhador, tanto intrínseca, entendida como própria do indivíduo, como extrínseca, vista na literatura como dependente das intervenções ou incentivos externos vinculados ao trabalho. Os resultados mostraram que a justiça empregada nas regras da recompensa monetária é uma característica que exerce influência na motivação intrínseca e extrínseca, enquanto a controlabilidade do sistema de promoção exerce influência na motivação extrínseca.

O último e sexto artigo, "Fotografar para Compreender: Relato de Experiência e Reflexões a partir das Lentes Trabalho, Gestão e Subjetividade", de autoria de Laura Alves Scherer, Marcia Cristiane Vaclavik e Carmem Ligia lochins Grisci, parte da ideia de que os modos de trabalhar têm implicações diretas na constituição do sujeito, buscando refletir sobre o uso da fotografia como potencializador da compreensão teórica em Administração. As autoras argumentam em favor da interação da arte com a produção científica, por entender que a experiência levou à qualificação do olhar e, assim, possibilitou novas formas de apreensão da teoria em campo.

Finalizando, gostaria de fazer um agradecimento especial à equipe de revisores e diagramadores da RECADM, Aline Uchida e Flávia Vianna, que permitiram ao periódico sair de uma situação de atraso nas publicações no ano de 2017 para a conclusão antecipada de todas as edições de 2018. Isso possibilitou que passássemos a disponibilizar os artigos no início do quadrimestre e não no seu fim, dando-os maior visibilidade no decorrer do ano. Devo também um agradecimento especial a André Guimarães, que não somente concluiu em tempo hábil todas as alterações de layout e design, mas fez com que o portal de periódicos IBEPES incorporasse as tecnologias mais recentes de gestão de informação editorial. Como sempre, agradeço aos revisores e autores que apostaram no nosso trabalho, alavancando a 
RECADM em número e relevância. Nunca recebemos tantos artigos como nesses últimos seis meses, como também nunca fomos tão eficientes no processo de avaliação, e isso é fruto da dedicação de autores e revisores. Para 2019, esperamos somente dar continuidade nesse processo de fazer editorial, pois avançamos muito. Sendo assim, alguma energia e atenção daremos à parte cerimonial do periódico, que envolve a tentativa de inclusão da RECADM em indexadores como Redalyc, Scopus e Web of Science.

Uma excelente leitura,

\section{Luciano Rossoni}

Editor da RECADM 


\section{Referências}

Alcadipani, R. (2017). Periódicos brasileiros em inglês: A mímica do publish or perish" global”. Revista de Administração de Empresas, 57(4), 405-411.

Bertero, C. O., Alcadipani, R., Cabral, S., Faria, A., \& Rossoni, L. (2013). Os desafios da produção de conhecimento em administração no Brasil, Cadernos EBAPE.BR, 11(1), 181-196.

Cabral, S., \& Lazzarini, S. G. (2011). Internacionalizar é preciso, produzir por produzir não é preciso. Organizações \& Sociedade, 18(58), 541-542.

Diniz, E. H. (2017). Periódicos brasileiros da área de Administração no contexto de internacionalização da produção científica. Revista de Administração de Empresas, 57(4), 357-364.

Farias, S. A. D. (2017). Internacionalização dos periódicos brasileiros. Revista de Administração de Empresas, 57(4), 401-404.

Fradkin, C. (2017). The internationalization of psychology journals in Brazil: A bibliometric examination based on four indices. Paidéia, 27(66), 7-15.

Goulart, S., \& Carvalho, C. A. (2008). O caráter da internacionalização da produção científica e sua acessibilidade restrita. Revista de Administração Contemporânea, 12(3), 835-853.

Goulart, S. (2018). O conhecimento local: produção, desafios e embates. Farol Revista de Estudos Organizacionais e Sociedade, 5(12), 268-296.

Larivière, V., Haustein, S., \& Mongeon, P. (2015). The oligopoly of academic publishers in the digital era. PLOS ONE, 10(6), e0127502.

Schmitt, J. (2014). Academic journals: The most profitable obsolete technology in history. The Huffington Post Blog. Recuperado em 31 de julho, 2018, de http://www. huffingtonpost.com/jason-schmitt/academic-journals-the-mos_1_b_6368204.html

\section{Apêndice: Análise da Variância das Citações}

Na Tabela 1, avalio o percentual de variância explicada das citações considerando a categorização dos artigos em termos de idioma (Português, Inglês e Espanhol), periódico (88 revistas listadas no Spell que constavam na base na época analisada) e ano de publicação (2012, 2013 e 2014). As três variáveis em conjunto explicam 18,5\% da variância das citações individuais dos artigos, em que todas elas foram significativas. Apesar do periódico com $15,1 \%$ de explicação da variância e o ano com 2,8\% terem uma explicação da variância superior ao do idioma (0,8\%), não significa que a diferença entre as médias de citações entre periódicos em Português, Espanhol e Inglês seja de baixa magnitude. Significa somente que a variação é maior entre as categorias das outras duas variáveis. Tendo isso em vista, a análise da variância foi realizada para estimar as médias que foram apresentadas na Figura 2 com o objetivo de controlar o efeito do ano e do periódico, pois analisar univariavelmente a diferença de médias entre os idiomas poderia desconsiderar o efeito do tempo de publicação e da atratividade de alguns periódicos. Também conduzimos análises de variância adicionais fazendo interações entre idioma, periódico e ano de publicação, mas nenhuma delas foram significativas, por isso as desconsideramos. 
Tabela 1. Efeito do Idioma, do Periódico e do Ano de Publicação nas Citações Recebidas.

\begin{tabular}{lccccc}
\hline & Soma dos Quadrados & df & F & Sig. & Efeito \\
\hline Modelo $^{\mathrm{a}}$ & 4769,32 & 91 & 16,48 & 0,000 & $18,5 \%$ \\
Idioma & 205,86 & 2 & 32,36 & 0,000 & $0,8 \%$ \\
Perí́dico & 3907,51 & 87 & 14,12 & 0,000 & $15,1 \%$ \\
Ano de Publicação & 716,92 & 2 & 112,68 & 0,000 & $2,8 \%$ \\
\hline Erro & 21045,96 & 6616 & & & \\
Total & 34469,00 & 6708 & & & \\
Total Corrigido & 25815,28 & 6707 & & & \\
\hline
\end{tabular}

a) $R^{2}=0,185\left(R^{2}\right.$ Ajustado $\left.=0,174\right), n=6708,88$ periódicos.

Em relação aos dados, selecionamos os artigos publicados entre 2012 e 2014 de periódicos que já constavam na base Spell desde aquela época (6.708 no total). Periódicos que foram incorporados posteriormente no Spell foram desconsiderados, pois poderiam não ter a mesma exposição. Qualquer outro tipo de documento como editoriais, casos de ensino, entre outros documentos que não se configuram como artigos também foram descartados. Deve-se ressaltar que a escolha dos anos de 2012 a 2014 se deu no objetivo de se manter um intervalo de exposição de pelo menos três anos das publicações recentes, pois todas as citações, obviamente, ocorrem depois que os artigos são publicados. Com isso, não faria sentido avaliar as citações de artigos imediatamente publicados. Nós avaliamos as citações em três anos seguidos para evitar efeitos pontuais e, ao mesmo tempo, ter maior variabilidade na comparação. Não estendemos a análise para antes de 2012, pois o comportamento das citações na área era distinto, até porque não havia a possibilidade de consulta no Spell antes desta data. 